\title{
SOSIALISASI ZERO WASTE DI DESA KEDIRI KABUPATEN LOMBOK BARAT
}

\author{
Wahyudi Zulfikar1 ${ }^{*}$ ), Ida Ayu Widhiantari, Guyup Mahardian Dwi Putra, Surya Abdul \\ Muttalib, Agriananta Fahmi Hidayat, Zulhan Widya Baskara \\ Program Studi Teknik Pertanian, Fakultas Tekologi Pangan dan Agroindustri, Universitas \\ Mataram, Jl.Majapahit No. 62, Mataram NTB \\ ${ }^{*}$ Korenpondensi: wahyudi.Z@unram.ac.id
}

Diterima 12 November 2020 / Disetujui 13 Desember 2020

\begin{abstract}
ABSTRAK
Sampah menjadi persoalan tersendiri di desa Kediri Kecamatan Kediri, kabupaten Lombok Barat. Hal ini dikarenakan tiap harinya di Lomboka Barat mencapai 175, 4 ton produksi sampah, namun kemampuan pengelolaan hanya ada $60.83 \%$, Sebanyak 101,76 ton atau $58,01 \%$ diangkut diangkut ke tempat pembuangn akhir. Kemudain 2,82\% diolah dengan pola 3R. Dari sekian banyak di antaranya merupakan sampah Organik, Sampah Anorganik dan sampah 9,95\% sampah yang sulit terurai berupa sampah plastic dan sampah B3. Adanya peran serta seluruh lapisan masyarakat dalam pengelolaan sampah maka pembekalan pengetahuan mengenai pengelolaan sampah perlu digalakkan. Berdasarkan analisis situasi, permasalahan yang dihadapi diwilayah tersebut belum sepenuhnya memiliki pengetahuan mengenai konsep Zero Waste serta minimnya ketrampilan dalam pengelolaan sampah Organik, sampah Anorganik, dan Sampah B3, sehingga pengelolaan sampah tidak maksimal. Adapun tujuan dari pelaksanaan program pengabdian ini adalah (1) Membekali pengetahuan masyarakat umumnya mengenai konsep Zero Waste dengan penerapan prinsip 5R (Refuse, Reduse, Reuse, Recycle, Rot). (2) Memberikan pengetahuan kepada masyarakat mengenai bahaya dari sampah, (3) Meningkatkan keterampilan masyarakat dalam memanfaatan sampah. Penyuluhan dilakukan oleh tim pengabdian kepada masyarakat dengan materi berupa; (1)Pengenalan tentang zerowaste (2) Pengenalan Produk Hasil dengan 5R (3) Pengenalan peralatan untuk pengolahan sampah dengan Prinsip 5R. Hasil kegitan menunjukkan bahwa masyarakat yang hadir telah mendapat pengetahuan dan wawasan tentang Zero Watse, Pengolahan sampah dengan prinsip $5 R$ yang dapat mengatasi masalah limbah rumah tangga dan mengubah limbahh tersebut menjadi berbagai produk yang mempunyai nilai ekonomi. Sehinga secara luas dapat mengatasi masalah sampah di Desa Kediri, Kecamatan Kediri Kabupaten Lombok Barat.
\end{abstract}

Kata Kunci: Zero Waste, sampah organiK, sampah anorganic dan sampah B3

\section{PENDAHULUAN}

Pertumbuhan penduduk di Indonesia saat ini semakin pesat. Hal ini berpengaruh pada sampah yang dihasilkan tiap orang. Sampah di
Indonesia banyak diproduksi oleh kotakota besar. Untuk produksi sampah per orangnya relatif kecil, yaitu 2-3 liter, jika diasumsikan setiap keluarga (rumah tangga) terdiri dari 4,5 jiwa, maka maksimal produksi sampah tiap rumah 
tangga adalah 13,5 liter. Berdasarkan Data Dinas Lingkungan Hidup dan Kehutanan NTB, Kota Mataram menghasilkan 314 ton sampah per hari, 273 ton diantaranya masuk ke TPA. TPA Pengengat seluas 10 hektare di Lombok Tengah, TPA ljo Balit dengan luas 8 hektare di Lombok Timur, TPA Jugil seluas delapan hektare di Lombok Utara. Sedangkan Kabupaten Lombok Barat menghasilkan 175,4 ton/hari, 101,76 ton diantaranya masuk ke TPA Kebon Kongok seluas 8,41 hektare untuk Kota Mataram dan Kabupaten Lombok Barat.

Kabupaten Lombok Barat terdiri dari 10 Kecamatan, 3Kelurahan, dan 119 Desa. Kepala Bidang Pengelolaan Sampah dan Limbah B3, Dinas Lingkungan Hidup Kabupaten Lombok Barat, I Gusti Ayu Swasti Astuti, menyebutkan produksi sampah di daerahnya mencapai 175,4 ton per hari. Dari total produksi sampah pemerintah hanya mampu menangani 60,83 persen. Sebanyak 101,76 ton atau $58,01 \%$ bisa diangkut ke tempat pembuangan akhir, sedangkan 4,95 ton atau 2,82 persen diolah dengan $3 R$. kemudian 9,95 persen berbentuk sampah yang sulit terurai. Bentuknya lebih banyak sampah plastik dalam praktiknya, sampah plastik tersebut harus mendapat perlakuan khusus karena membutuhkan waktu yang sangat lama untuk terurai. Sampah menjadi salah satu hal yang perlu diperhatikan saat ini karena bisa menyebabkan banyak permasalahan. Sampah menyebabkan bumi kita menjadi tercemar dan timbulnya berbagai persoalan lain. Setiap orang di bumi ini pastinya menghasilkan sampah. Bila setiap orang tidak dapat mengurangi sampah per harinya, maka hal buruk akan terjadi di kemudian hari.

Warga Lombok Barat mulai mengeluhkan sampah yang menumpuk di mana-mana, lantaran tak bisa dibawa ke TPA Kebon Kongok. Tumpukan sampah ini berada di jalan raya dan gang-gang perkampungan warga. Sampah ini pun menimbulkan bau tak sedap. khawatir, tumpukan sampah ini akan memicu timbulnya penyakit. Langkah sementara yang dilakukan warga berinsiatif membakar sampah di sekitar lokasi penampungan. Salah satu daerah terdampak penumpukan sampah lumayan parah, yakni Desa Rumak Kecamatan Kediri. Pantauan Sekda Lombok Barat (Lobar) Dr. H. Baehaqi yang meninjau tumpukan sampah di TPS Dusun Pelowok Desa Kediri. Tumpukan sampah yang berada di pinggir jalan raya telah lama menjadi keluhan karna mengganggu pengendara yang melalui jalur penghubung di perbatasan Lombok Barat dengan Lombok Tengah tersebut. Tumpukan sampah yang meluber ke jalan raya menimbulkan bau tak sedap.

Kurangnya pemahaman masyarakat akan pengelolaan dan pemamfaatan limbah sampah rumah tangga menjadikannya sesuatu yang tidak memiliki nilai guna, membuat permasalahan sampah yang makin menumpuk, sehingga diperlukan pengenalan terhadap pengelolaan serta pemanfaatan limbah tersebut menjadi suatu produk yang memiliki nilai guna. Dengan adanya kegiatan pengabdian kepada masyarakat melalui kegiatan sosialisasi Zero Waste diharapkan dapat menjadikannya sebagai sarana atau solusi alternatif dari keberadaan limbah sampah rumah tangga yang melimpah dan belum termanfaatkan sehingga dapat mengatasi masalah pencemaran lingkungan serta diharapkan mampu meningkatkan pertumbuhan ekonomi masyarakat. Zero Waste Lifestyle bukanlah suatu hal yang baru. Banyak negara sudah memulainya sejak lama. Beberapa negara seperti Amerika, Australia, Swedia, Selandia Baru, dan beberapa negara Eropa lainnya sudah menerapkan konsep tersebut untuk 
menjadi solusi konkret pengelolaan sampah. Di Indonesia kebijakan Zero Waste Lifestyle belum dicanangkan secara nasional, namun beberapa kota sudah memulainya dalam bentuk program Zero Waste Cities. Sebagai contoh, di Provinsi Jawa Barat ada 3 kota yang ditargetkan menjadi kota percontohan penerapan konsep Zero Waste Cities, yaitu Kota Cimahi, Kota Bandung, dan Kabupaten Bandung. Yang terakhir adalah kebijakan Provinsi Bali yang menyatakan bahwa mulai tahun 2019 Bali melarang penggunaan kantong plastik sekali pakai. sehimgga kita bisa memulainya dari diri sendiri, keluarga dan lingkungan kita.

Untuk mendukung gerakan $5 \mathrm{R}$ dan menumbuhkan Zero Waste Lifesyle ini perlu adanya kolaborasi dari semua pihak, baik pemerintah, swasta, dan terutama masyarakat sebagai penyumbang dan penerima dampak negatif pencemaran. Namun, tanpa harus menunggu kita bisa menyadari arti penting menjaga lingkungan dengan memulai Zero Waste Lifestyle dari diri kita dan lingkungan terkecil.

Berdasarkan permasalahan yang telah dipaparkan, maka solusi yang ditawarkan adalah dengan memberikan pemahaman, keterampilan dalam mengolah limbah rumah tangga dengan prinsip 5R. singkatan dari Reduce, Reuse, Recycle. Menurut Bea Johnson dari Zero Waste, ada tambahan 2R, yakni Refuse dan Rot, Zero Waste Lifestyle melalui gerakan 5R yang dipopulerkan oleh Bea Johnson, yaitu Refuse, Reduce, Reuse, Recycle dan Rot atau dalam Bahasa Indonesia berarti Menolak, Mengurangi, Menggunakan Kembali, Mendaur Ulang, dan Membusukkan.

1. Refuse (Menolak), menolak barang yang sekiranya akan menghasilkan sampah, kita bisa menolak kantuk plastik nonbiodegradable saat berbelanja. Tentu kita pun harus mempersiapkan kantung belanja sendiri dari rumah.

2. Reduce (Mengurangi), kita dapat menghindari pemakaian dan pembelian produk yang menghasilkan sampah dalam jumlah besar. Selain itu, kita bisa menggunakan produk yang dapat diisi ulang.

3. Reuse (Menggunakan kembali), kita dapat menggunakan kembali wadah/kemasan dengan fungsi yang sama secara berulang-ulang. Contohnya menggunakan baterai recharge, menggunakan plastik bekas minyak goreng sebagai pengganti polybag.

4. Recycle (Mendaur ulang), kita dapat menggunakan produk dan kemasan yang dapat didaur ulang dan mudah terurai. Selain itu, kita juga dapat melakukan penanganan sampah organik menjadi pupuk kompos. Serta melakukan penanganan sampah anorganik menjadi barang yang bermanfaat.

5. Rot (Membusukkan) Membusukkan barang yang dikonsumsi, poin ini hanya bisa diterapkan pada barang dan sampah organik yang mudah terurai, seperti membusukkan sampah organik menjadi pupuk kompos. Salah satunya dapat dilakukan dengan cara membuat lubang biopori. Hal ini tentu saja dapat mengurangi beban TPA secara signifikan.

Dalam menerapkan Zero Waste secara sungguh-sungguh, $3 R$ saja tidak cukup, karena Zero Waste tidak hanya sekadar mendaur ulang sebanyak mungkin, namun sebaliknya. 5R (Refuse, Reduce, Reuse, Recycle, Rot), bisa digunakan sebagai prinsip untuk mengarah pada cara hidup sehat tanpa limbah, dan bisa diterapkan untuk gerakan gaya hidup ramah lingkungan. Dengan memberikan pengetahuan 
tentang Zero Waste dan pelatihan 5R (Refuse, Reduce, Reuse, Recycle dan Rot) kepada kelompok masyarakat setempat diharapkan masyarakat khususnya di Desa Kediri akan memiliki keahlian dalam megolah dan memanfaatkan limbah rumah tangga guna tercapainya tujuan dari Zero Waste.

\section{Target Luaran}

Luaran yang diharapkan dari program pengabdian ini antara lain kelompok sasaran memiliki pemahaman tentang zerowaste dan keterampilan dalam mengolah sampah rumah tangga dengan prinsip 5R. serta kegiatan ini juga akan dipublikasikan pada jurnal dan media massa elektronik.

\section{METODE PELAKSANAAN}

Kegiatan pengabdian pada masyarakat ini akan dilaksanakan dalam beberapa tahapan. Adapun tahapan kegiatan sebagai berikut:

1. Melakukan survey

Kegiatan survey dilakukan untuk mengetahui potensi limbah rumah tangga baik sampah organic, anorganik, dan B3

2. Penyuluhan

Kegiatan penyuluhan yang dilakukan oleh tim pengabdian merupakan suatu bentuk pendampingan pembelajaran prinsip 5R, Pemberian materi yang terkait akan memberikan gambaran bagi peserta atau kelompok untuk tahapan kegiatan selanjutnya. Kegiatan penyuluhan ini nantinya akan diikuti oleh kelompok dan masyarakat setempat serta melibatkan pemuda desa di wilayah tersebut.

\section{Pendampingan Pelatihan}

Pendampingan pelatihan merupakan bentuk kegiatan praktek dari teori yang telah diberikan sebelumnya. dapat memotivasi kelompok untuk terus dapat memanfaatkan potensi limbah yang ada menjadi produk yang bernilai ekonomi dengan prinsip 5R.

4. Evaluasi

Evaluasi dilakukan untuk mengetahui kemampuan dan keberhasilan kelompok dalam menyerap materi dan melakukan praktek pengolahan limbah rumah tangga dengan prinsip $5 R$.

\section{HASIL DAN PEMBAHASAN}

\section{Persiapan}

Sebelum kegiatan pengabdian dilaksanakan, tim pengabdian melakukan persiapan terlebih dahulu agar kegiatan dapat berjalan dengan lancar. Persiapan yang dilakukan mulai dari melakukan survey untuk dapat melakukan koordinasi dengan kepala desa dalam hal menentukan dan menyepakati jadwal penyuluhan di lokasi tersebut sesuai dengan kondisi peserta.

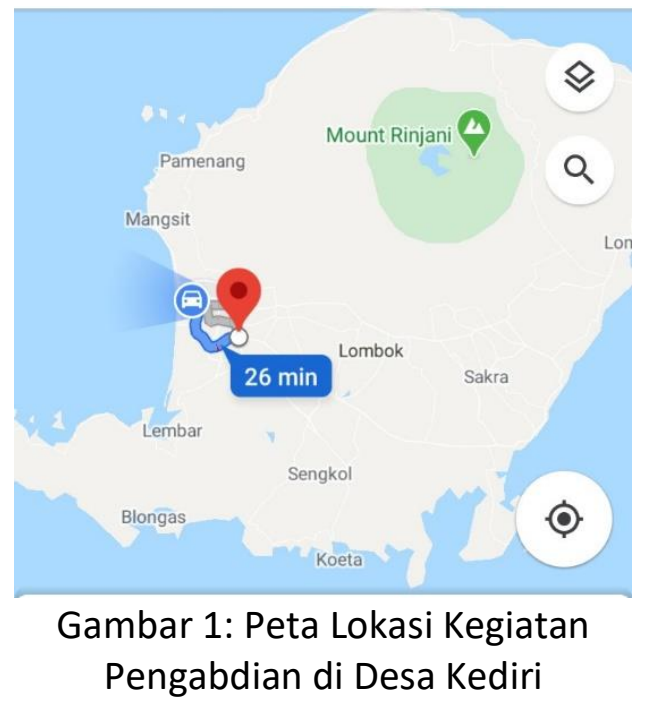

Persiapan selanjutnya yaitu menyiapkan materi untuk sosialisasi zerowaste, menyiapkan daftar hadir peserta, menyiapkan susunan acara, dan menyiapkan alat dan bahan yang dibutuhkan untuk sosialisasi zerowaste. Dari hasil koordinasi, maka disepakati bahwa pelaksanaan kegiatan pengabdian 
dilaksanakan pada tanggal 5 September 2020 pukul 10.00 WITA. Kegiatan pengabdian dilaksanakan di rumah seorang warga di Karang Kuripan Baru, Kabupaten Lombok Barat yang dihadiri oleh kepala Dusun Karang Kuripan Baru,kepala desa kediri pada saat itu sedang berhalangan hadir serta warga sekitar yang sebagaian besar adalah bapak-bapak dan ibu-ibu dari berbagai kalangan profesi, dari wiraswasta sampai ASN serta anak-anak usia kelas 5 sekolah dasar.

\section{Pelaksanaan}

Kegiatan diawali dengan acara sambutan dari wakil kepala Desa setempat yang diwakilkan oleh kepala dusun setempat, yang kemudian dilanjutkan dengan penyampaian materi sosialisasi oleh tim pengabdian, pengenalan produk-produk hasil zerowaste, diskusi, dan yang terakhir penutupan.

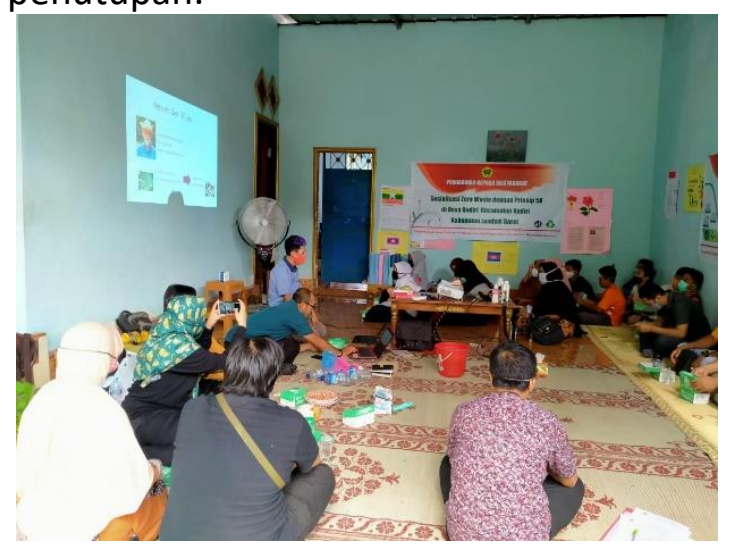

Gambar 2: Penyampaian Materi Zero Waste dengan $5 R$

Setelah salam perkenalan dari tim pengabdian, kami menyampaikan bebrapa materi sebagai pengetahuan dasar untuk membuka wawasan masyarakat mulai dari sejarah Zero Waste, konsep dan tujuan Zero Waste, kemudian kami masuk ke pemaparan tentang berbagai jenis sampah serta pemilahnnya, dan masa penguraian oleh alam dan materi inti yaitu konsep Zero Waste dengan 5R. dengan penyampaian yang singkat padat dan jelas dan menarik untuk disimak seperti pada gambar bawah ini.

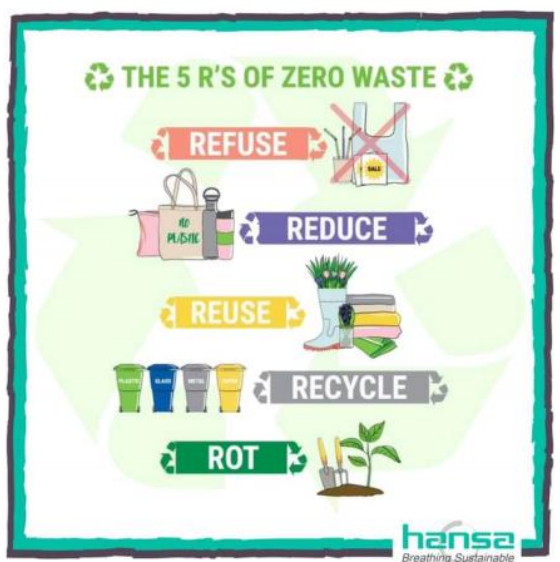

Gambar 3: Contoh Materi Inti Zero Waste yang disampaikan

Dalam penyampaian materi Zero Waste, warga desa tersebut memang belum memahami manfaat yang diperoleh dari pengolahan limbah rumah tangga tersebut dengan prinsip $5 \mathrm{R}$, yang mereka biasa lakukan adalah hanya membuang atau membakar limbah rumah tangga tersebut tanpa adanya pengolahan tertentu yang dapat meningkatkan nilai ekonomi. Dengan pemaparan materi ini majadikan warga Desa Karang Kuripan Baru mendapatkan ilmu yang cukup luas dalam memanfaatkan limbah rumah tangga manjadi suatu produk baru yang memiliki manfaat. Setelah penyampain materi pengetahuan dasar tentang Zero Waste berikut dengan prinsip-prinsip yang digunakan dalam mendukung terciptanya zerowaste dengan 5R pada masyarakat, disajikan pula berbagai jenis produkproduk yang menarik yang dihasilkan dari limbah rumah tangga. sehingga informasi ini sangat bermanfaat untuk peserta dengan harapan peserta mampu mengembangkannya dikemudian hari. Materi yang disampaikan meliputi pemanfaatan dan pengolahan limbah rumah tangga menjadi berbagai macam produk kerajinan. 


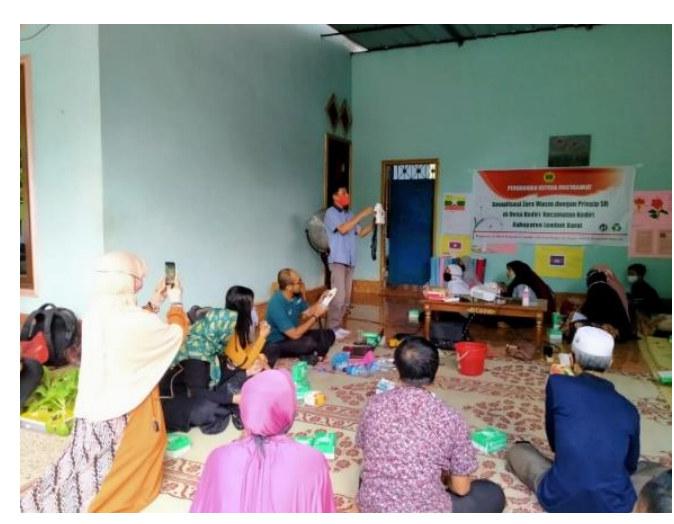

Gambar 4: Pengenalan Produk-Produk dari Pemanfaatan Limbah Rumah Tangga

Produk-produk dari limbah rumah tangga yang kami perkenalkan antara lain: baju, rompi tas selempang, ransel untuk laki-laki dan ransel untuk perempuan yang terbuat limbah dari karung goni. Kemudian ada wadah makan tradisional (inke) dari gelas plastik, miniature vespa dari kaleng minuman, tas selempang dari jerigen kecil baik yang biasa sekaligus yang include senter LED dan charger Hand Phone. Dengan adanya produk-produk dari limbah rumah tangga yang mempunyai menarik baik dri segi bentuk, warna dan corak serta pembuatan yang sangat mudah serta bahan baku yang sangat mudah didapatkan dari berbagai jenis limbah rumah tangga dan yang paling penting bernilai ekonomi. Dengan adanya sosialisasi Zero Waste diharapkan bisa menggugah semanagat masyarakat untuk mulai bergerak dalam memanfaatkan limbah rumah tangga dengan prinsip $5 R$ yang bemuara pada terciptanya gaya hidup Zero Waste.Berikut kami tampilkan bebrapa produk-produk dari limbah:

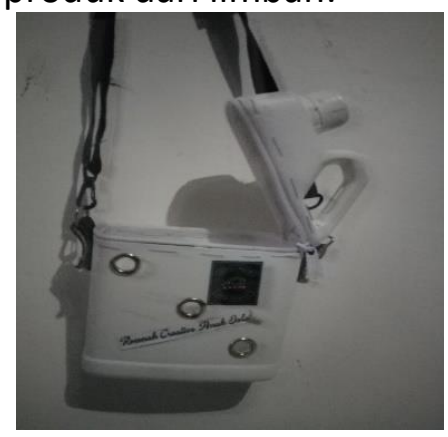

Gambar 5: Tas Selempang Dari Jerigen

Bekas Penampung Air Radiator Motor

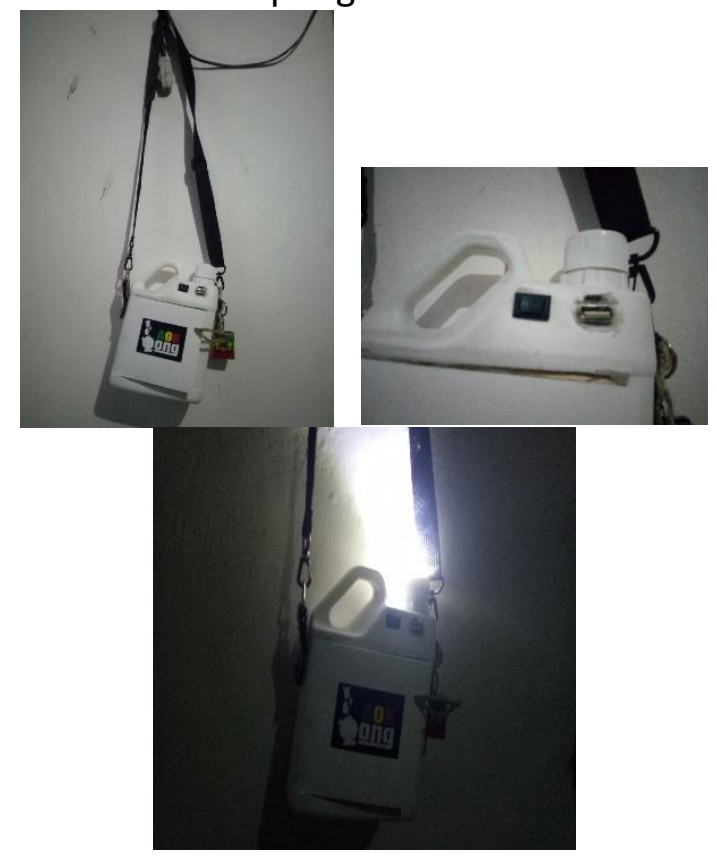

Gambar 6: Tas Selempang dengan Tambahan Senter LED dan Power Bank

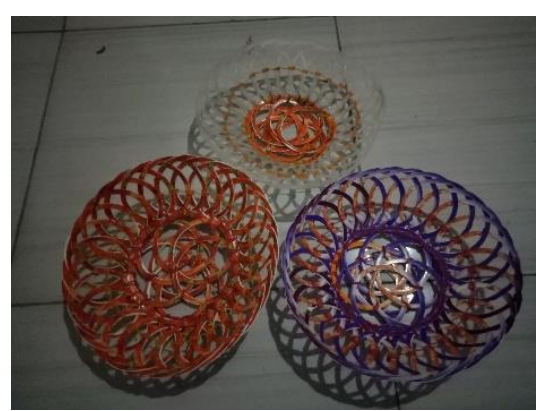

Gambar 7: Wadah Makan (Ingke) dari Gelas Minuman

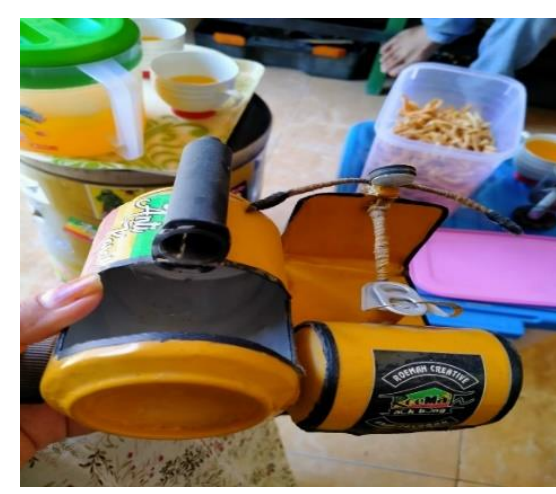

Gambar 7. Miniatur Vespa Dari Kaleng Minuman Aluminium 


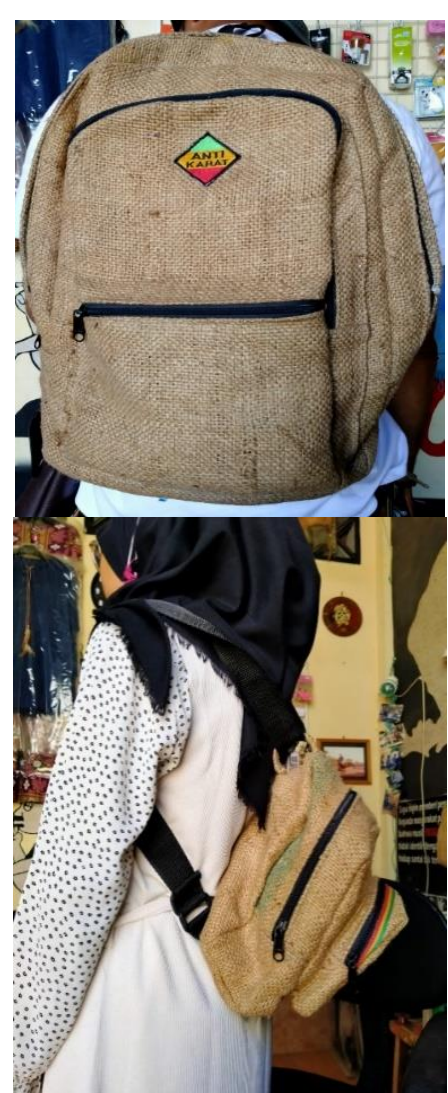

Gambar 8: Ransel Dari Limabah Serat Karung Goni

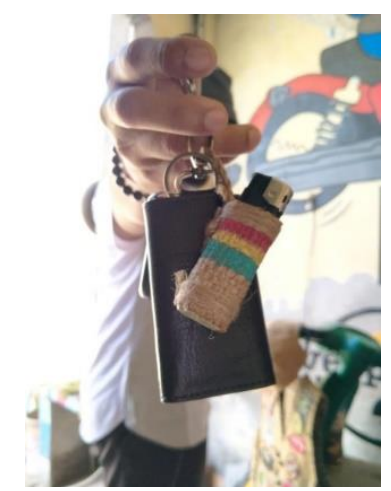

Gambar 9: Cover Korek Api Dari Limbah

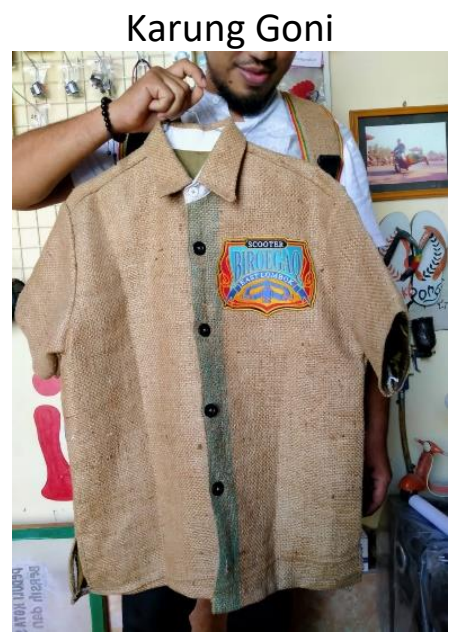

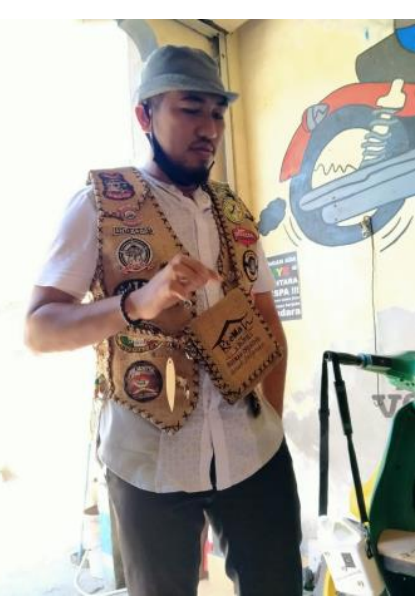

Gambar 10. Seragam, Tas Selempang dan

Rompi Dari Limbah Karung Goni

Ditengah sesi perkenalan produkproduk yang dibuat dari limbah rumah tangga, masyarakat cukup antusias berdiskusi mengenai produk yang ada, baik fungsi dan lain-lain, sekaligus menjelaskan bagaimana cara pembuatan bahan serta alat yang dignakan dalam pembuatan produk-produk tersebut, dalam rangka menjawab pertanyaanpertanyaan yang ditanyakan oleh peserta sampai tahap akhir dari kegiatan pengabdian melalui sesoliasi Zero Waste dengan prinsip $5 R$ tersebut.

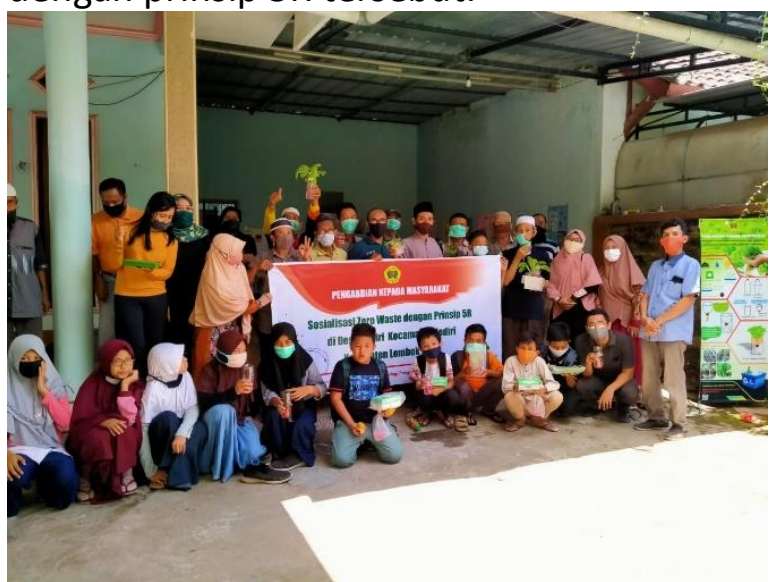

Gambar 11: Foto Bersama Peserta Sosialisasi

\section{KESIMPULAN DAN SARAN}

\section{Kesimpulan}

Sosialisasi Zerowatse dengan 5R yang diadakan Dusun Karang Kuripan Baru kabupaten Lombok Barat berjalan dengan 
baik, dimana peserta sangat antusias dalam mengikuti seluruh rangkainan kegiatan Para peserta memiliki wawasan yang lebih mengenai zerowaste dengan prinsip 5R sebagai gaya hidup. Peserta yang hadir menjadi mengetahui cara pemanfaatan limbah rumah tangga dengan prinsip $5 R$ zerowaste menjadi berbagai produk yang bisa mempunyai nilai ekonomi.

\section{Saran}

Saran yang dapat diberikan untuk perbaikan kegiatan pengabdian ini yaitu sosialisasi-sosialisasi terkait zerowaste agar terus bisa dilakukan secara berkelanjutan agar mindset gaya hidup sehat tanpa limbah dengan $5 R$ bisa diterapkan dengan sutuhnya untuk menuju kehidupan yang lebih baik.

\section{UCAPAN TERIMA KASIH}

Untuk terselenggaranya kegiatan ini disampaikan terimakasih atas dukungan biaya dari DIPA BLU Universitas Mataram Tahun Anggaran 2019, dengan Surat Perjanjian Nomor: 2255/UN18/ LPPM/2020 Tanggal 04 Mei 2020

\section{DAFTAR PUSTAKA}

Antara NTB, 2019. Buruknya Pengelolaan Sampah Di Desa Kediri: http://mataram-antaranews-com

Ayendra Dinda Naila, 2020, Yuk kita Terapkan Zero Waste dengan 5R: http://Kompasiana-com

Johnson, B. 2013. The 5R of Zero Waste: The Ultimate Guide to Simplifying Your Life by Reducing Your Waste. New York: Simon and Schuster.

Kristina. 2014. The 5R (Refuse Reduce Reuse Repurpose Recycle). Dipetik Februari 17, 2019, dari thegreeningofwestford: http://thegreeningofwestford.com /2014/04/5-rs-refuse-reducereuse-repurpose-recycle.html

Shia. 2015. The $5 \mathrm{R}$ of Zero Waste. Dipetik Maret 9, 2019, dari wastelandrebel:

https://wastelandrebel.com/en/au thor/shia/

SuaraNTB, 2020 Sekda Lobar melarang warga Lombok tengah membuang sampah di TPS kediri. http://wwwsuarantb.com

Syahbani Tiara Syahra, 2020. Cara Pintar Memilah Dan Mengolah Sampah: https://www.99.co/blog/indonesia /mengelola-sampah/ 